\title{
Performance Management in Collaborative Networks: Difficulties and Barriers
}

\author{
Juan-Jose Alfaro-Saiz, Raul Rodríguez-Rodríguez, and María-José Verdecho \\ Centre d'Investigació de Gestió i Enginyeria de Producció, \\ Universitat Politècnica de València, Camí de Vera s/n, 46022 València, Espanya \\ jalfaro@omp.upv.es
}

\begin{abstract}
Global competitiveness obliges to enterprises to collaborate in many processes such as new product and services development in order to shorten the lifecycle, development and commercialization. Therefore, the competence has drifted from an individual focus to a supply chain management one and, from some years, to a collaborative enterprises network approach. It is common to find frameworks for measuring/managing the performance within extended enterprises, supply chains, virtual enterprises, etc. However, few authors deal with a higher level: the collaborative networks one. This concept of enterprises management set up bigger difficulties regarding not only from a conceptual and structural point of view but also considering both the design and posterior development of systems capable of managing the performance achieved in this type of organizations. This work describes both the main difficulties and barriers when trying to apply performance management concepts to collaborative networks. In this sense, it is highlighted the weaknesses of the existing intra-organizational frameworks that cannot be projected, as they are conceived, to manage performance within collaborative networks.
\end{abstract}

Keywords: Performance management system, Collaborative enterprise networks.

\section{Introduction}

One of the strategies used to compete and adapt to global market needs is cooperation among organizations. Thus, searching for new business opportunities reaches a dimension of shared effort and responsibility in order to improve the quality of the products and services. Competitiveness has shifted from an individual factor to be dependent on the whole value chain of the product and/or service offered. Several authors affirm the importance of this thematic, [1] affirms, "the battleground of the next decade will be Supply Chain versus Supply Chain. Are you measuring the right things to win this battle?".

Nevertheless, today, it is not even enough to deal with the complexity of supply chains but more complex environments such as collaborative enterprise networks, which may embed to one or more supply chains. Thus, complex inter-organizational environments are composed of enterprises that are not only sharing flows of information, materials, etc. upstream and downstream (concept of supply chain) but 
these flows may also be without a lineal reference of products under a more or less common strategy. In this type of contexts, various enterprises and/or supply chains participate in the development of products where the customer differs that is to say the same enterprise is involved in several supply chains with different objectives, strategies, etc.

This type of inter-organizational contexts has a higher level of complexity that the one of the supply chains, and then, their performance management should be dealt with management systems able to integrate all the necessary elements to measuremanage them efficiently and effectively. Although a few years ago the interest of different forums (managers, researchers, etc.) was focused on performance measurement related to the Supply Chain, it is possible in the coming years will see a clear trend regarding Collaborative Enterprise Networks (CEN).

However, it is observed a lack of works regarding elements for measuring and managing relevant factors of the Collaborative Enterprise Networks, such as collaborative activities, inter-organizational relationships, common or global objectives of the Supply Chain, etc. Collaborative relationships will require suppliers and consumers to support multiple simultaneous business models and communication media in order to fully realise the benefits of collaborative business.

The research followed a constructivist approach, based on the following activities: recompilation, analysis and study of scientific knowledge, acquisition of main postulates and construction of initial classification [2]. The initial elements considered in the present constructivist approach were the following:

- The performance measurement/management evolution.

- The difficulties/barriers to performance management in CEN.

- The analysis of performance management systems within collaborative networks domain.

After this introduction, this paper describes the evolution of the performance measurement-management from individual contexts to Collaborative Enterprise Networks contexts. Then, difficulties and barriers to performance management in Collaborative Enterprise Networks are enumerated. Next, performance management systems in this context are analyzed. Finally, conclusions are exposed.

\section{Performance Measurement/Management Evolution: Frameworks}

Performance measurement-management systems have evolved in order to adapt to complexity of organizations. Initially, they were developed for intra-organizational contexts (individual level). Then, systems for dealing with supply chains (interorganizational level) appeared. Recently, systems that try to manage CEN under an integrated approach have been developed. The intra-organizational domain has been widely studied in the literature, with various classifications and different models and frameworks such as the works by [3], [4], [5] and [6]. Later, at the end of 1990's, many concepts developed for intra-organizational performance measurement-management domain were adapted to inter-organizational domains in order to deal with supply chains. In this sense, in the literature, many works were developed; some of them from a 
theoretical point of view due to the difficulty of apply them in real contexts. Finally, some works have appeared that try to deal with domains that are more complex that supply chains. Thus, the works developed define complex frameworks to amplify performance measurement-management to enterprise networks that are more sophisticated. It is important to note the works by [7], [8], [9] and [10].

In addition, there are other types of works that describe performance measurement systems to measure some collaboration aspects ([11], [12], [13]) or virtual organizations ([14] and [15]) that may be included with some nuances in the domain of CEN.

\section{Difficulties/Barriers to Performance Management in CEN}

Performance management in CENs is not an easy task. As it cannot be managed what has not been measured before, the first aspect that has to be done is measuring its performance so that it can be managed.

CEN present a set of special characteristics that are difficulties for performance measurement systems that were not developed for this type of structures. After the analysis of the different works in the literature ([7], [16], [17], [18], [19], etc.) initially focused on structures more simple than CENs, a summary has been performed of the main difficulties/barriers that come up to this type of organization. In the next paragraphs, it is exposed the main difficulties/barriers to performance management in CENs distinguishing into four groups: A) Dynamicity and flexibility, B) Global vision, C) Broadness and D) Information systems role: intra-inter-organizational interface.

A) Dynamicity and Flexibility: enterprises have to adapt to all types of changes that occur (technological, organisational, economical, social, commercial, etc.). This circumstance affects production and organisational structures from both intra and inter-organisational points of view. This is a highly sensitive factor for CEN as any change in an enterprise may influence the global performance of the whole CEN without evidence of its appearing. From a point of view of CEN performance management, it is very important an adequate adaptation of each enterprise belonging to the CEN. There are many implications to consider:

- The CEN global performance management has to be flexible and sensitive to detect dysfunctionalities that these changes may involve and has to have mechanisms that allow modifying easily the performance measurement elements if necessary (it is usually necessary). In this sense, it is a common situation to redefine objectives and/or strategies and their corresponding performance indicators. Modifying the performance measurement-management elements is quite delicate (it has to be taken into account the priorities of the CEN, a perfect coherence among elements and maintain equity within the CEN) due to the high interaction among enterprises.

- The possibility of being affected any member of the CEN without the knowledge of its existence may oblige to re-make a part of the performance measurement system which involves time, effort and loss of control of the organization during that period.

- The incorporation or disappearance of members within the CEN also affects performance measurement systems in the same way as previously stated. In 
addition, this circumstance may obligate to establish new equity and trust relationships among their members and, consequently, reaching of consensus which involves new mechanisms of coordination and organization. If equity does not exist among the enterprises participating within the CEN, it is practically impossible to create an environment of trust that enables the information exchange necessary to reach an adequate degree of efficiency from a global point of view. Performance measurement systems may include structured mechanisms highly automated to deal with these situations.

B) Global vision: CEN performance management also means to provide a global vision. This vision is related to the use of performance measurement-management elements (objectives, strategies, key performance indicators, etc.) that aid to measure and manage not only dyad inter-enterprise efficiency and effectiveness but also the whole CEN. This is complex requirement due to CEN dimensions.

This implies that global indicators are to be defined and those indicators should correspond to global CEN objectives and strategies. The use of global indicators should be a consequence of a clear structure of relationships that give response to various basic questions:

- What measurement elements have been specifically defined to measure-manage the global vision of the CEN?

- Are the global measurement-management elements related to partial measurement-management elements (intra-organizational level)? How do they influence each other?

- What has been each KPI defined at the global level for?

- What is improved in the CEN through its measurement-management?

CEN competitiveness is not only dependent on the interaction of the processes within enterprises. It is also needed to design and implement mechanisms that allow managing the whole CEN within performance measurement-management systems. This circumstance affects the phase of the design as well as the phase of implementation and management of the indicators and the rest of performance measurement elements used.

C) Broadness: The concept of CEN broadness makes reference to the number of partners that belongs to the CEN. The bigger the number of partners, the higher effort is needed to manage the global performance and obviously, the scalability requirements should be taken into account. This fact may be translated into the following consequences:

- Higher difficulty to establish common objectives and strategies for all the organizations that participate in the CEN. If enterprises are to be competitive and its relationship is to be sustainable, it is needed that all the members focus on strategic aspects of the business and that they have been established by consensus.

- Higher difficulty to select partial and global indicators.

- Increase in the quantity of information to be managed from a global point of view and higher difficulty in maintaining trust among the partners so that information is shared with the rest of partners. 
- Higher difficulty in establishing linkages and equity relationships that sustain trust in order to collaborate and distribute benefits proportionally among all CEN partners. This element (equity) is very important to create a conscious and trust climate that provides the necessary information to manage CEN from a global perspective with an adequate degree of efficiency.

D) Information Systems role: intra and inter-organizational interface: Another important element for CEN performance management is the use of integrated management tools that support CEN members.

It is usual that when defining performance measurement-management elements (that derivate from the performance measurement system) needed to CEN management, it is also defined the data needed to compute them and the source of that information, that is: who will provide each piece of information? How is he/she going to provide it? And at what time he/she will do it? Precisely, in this moment, discrepancies among the CEN members may appear as some of them may have difficulties to provide such data due to several reasons: information treatment (lack of resources), being unable to provide it in the right time (lack of resources) or not being able to obtain the data (lack of resources). The quantity of needed information to manage CEN is large and demands that the performance management system used provide a structure (information architecture) able to support all the data. This circumstance is vital as if common platforms are not used for uploading, transmitting and managing the data, it is practically unfeasible, from a practical point of view, that the system survives.

Currently, the use of internal information systems (based on ERs and other tools) and Web Services facilitates information management but also data homogenization and standardization mechanisms are needed. In addition, privacy policies should be established through controlled access, especially on that information sensitive to third party.

\section{Analysis of Performance Management Systems within Collaborative Networks Domain}

In this section, the most relevant performance management systems for CENs are reviewed. As explained en section two, there are four systems that stand out: [7], [8], [9] and [10]. Then, those systems are analyzed (see Table 1) regarding to the degree of consideration of the difficulties/barriers identified in section 3 .

Table 1. Analysis of PMS for CEN

\begin{tabular}{|l|c|c|c|c|}
\hline & \multicolumn{4}{|c|}{ Difficulty / Barrier } \\
\hline PMS & Dynamicity - Flexibility & Global vision & Broadness & I.S. role \\
\hline Bititci et al. (2005) [7] & $* *$ & $* * *$ & $* * *$ & $*$ \\
\hline Folan \& Browne. (2005) [8] & $*$ & $* *$ & $* * *$ & $*$ \\
\hline Gaiardelli et al. (2007) [9] & $*$ & $*$ & $*$ & \\
\hline Alfaro et al. (2005) [10] & $* *$ & $* * *$ & $* * *$ & $*$ \\
\hline - If the PMS does not deal with the barrier/difficulty, it is represented by ( ). \\
- If the PMS deals with the barrier/difficulty weakly, it is represented by (*). \\
- If the PMS deals with the barrier/difficulty moderately, it is represented by (**). \\
• If the PMS deals with the barrier/difficulty widely, it is represented by (***). \\
\hline
\end{tabular}


The main strengths of the EE PM model [7] are: that it makes explicit within the structure of the PMS the definition of performance indicators for measuring coordination through the interorganisational processes at both strategic and operational levels; makes explicit coordination measurement within the whole interorganisational processes that take part in the PMS structure. Folan \& Browne [8] developed a PMS for Extended Enterprise including mechanisms that measure the degree of contribution of each partner to the partnership (common interorganisational strategy), moreover, CEN broadness is very well treated. Gaiardelli et al. [9] develop a PMS (for the automotive after-sales service network) that is composed of four functional levels: business, process, activity and organisational unit, and development and innovation. Its strength lies in the connection made on interorganisational processes, although not seen a common strategy for the global network. Finally, Alfaro et al. (2007) provide a PMS that follows a top-down methododology from strategy to core process decomposition and ends with the stage of follow-up and monitoring. Emphasized in the ability to measure intra and inter-aspects and defining common performance measurement elements for all CEN. On the other hand, has an acceptable architecture to address certain dynamism in the CEN.

As can be observed in Table 1, none of the relevant PMS is a soundness system that deals with the main difficulties/barriers of CEN. The aspects that are less considered are those related to dynamicity-flexibility as well as the role of Information Systems and its integration.

\section{Conclusions}

Collaborative enterprise networks are a typology of organizational structure that currently is used to deal with the competitive requirements of global market. Thus, this structure has to be analyzed and studied broadly in order its reaches efficiency. One of the challenges is the development of performance management systems able to meet the complexity associated to this type of structure which can be observed under various perspectives. The existence of this complexity presents a set of difficulties/barriers that prevent current PMS deal with its tasks properly. In this work, the main difficulties/barriers and their implications in performance measurement-management have been described by grouping them into four types: A) Dynamicity/Flexibility, B) Global vision, C) Broadness and D) Information systems role: intra and inter-organizational interface.

In addition, it has been provided a brief review of PMS evolution from the individual enterprise domain to $\mathrm{CEN}$ domain in order to perform later an analysis of the PMS within CEN domain regarding the four difficulties/barriers. After the analysis, it is observed that it is still necessary to study further this type of structures in order to define PMS able to adapt to these contexts.

\section{References}

1. Hausman, W.H.: Supply chain performance metrics. The practice of supply chain management: Where theory and application converge. Kluwer Academic Publishers, Dordrecht (2003) 
2. Coughlan, P., Coughlan, D.: Action research: action research for operations management. International Journal of Operation and Productions Management 22(2), 220-240 (2002)

3. Kaplan, R.S., Norton, D.P.: The balanced scorecard. Measures that drive performance. Harvard Business Review, 71-79 (January/February 1992)

4. Bourne, M.: Designing and implementing a balanced performance measurement system. Control - Official Journal of the Institute of Operations Management, 21-24 (July/August 1999)

5. Neely, A., Adams, C.: Perspectives on Performance. The Performance Prism' Web Site of Neely A (2001), http: / /www.som. cranfield.ac.uk/som/cbp/adn.htm

6. Hronec, S.M.: Vital Signs. Amacom, New York (1993)

7. Bititci, U.S., Mendibil, K., Martinez, V., Albores, P.: Measuring and managing performance in extended enterprises. International Journal of Operations \& Production Management 25(4), 333-353 (2005)

8. Folan, P., Browne, J.: Development of an extended enterprise performance measurement system". Production Planning \& Control 16(6), 531-544 (2005)

9. Gaiardelli, P., Saccani, N., Songini, L.: Performance measurement systems in the after-sales service: an integrated framework. International Journal of Business Performance Management 9(2), 145-171 (2007)

10. Alfaro, J.J., Ortiz, A., Rodríguez, R.: Performance measurement system for Enterprise Networks. International Journal of Productivity and Performance Management 56(4), 305334 (2007)

11. Romero, D., Galeano, N., Molina, A.: A conceptual Model for Virtual Breeding Environments Value System. In: Camarinha-Matos, L., Afsarmanesh, H., Novais, P., Analide, C. (eds.) Establishing the Foundation of Collaborative Networks. Springer, Heidelberg (2007)

12. Msanjila, S.S., Afsarmanesh, H.: Trust analysis and assessment in virtual organization breeding environments. International Journal of Production Research 46(5), 1253-1295 (2008)

13. Bititci, U., Turner, T., Mackay, D., Kearney, D., Parung, J., Walters, D.: Managing synergy in collaborative enterprises. Production Planning \& Control 18(6), 454-465 (2007)

14. Chalmeta, R., Grangel, R.: Performance Measurement Systems for Virtual Enterprise Integration. International Journal of Computer Integrated Manufacturing 18(1), 73-84 (2005)

15. Francisco, R.D., Azevedo, A.: Dynamic Performance Management In Business Networks Environment. In: Digital Enterprise Technology. Springer, US (2007)

16. Busi, M., Bititci, U.S.: Collaborative performance management: Present gaps and future research. International Journal of Productivity and Performance Management 55(1), 7-25 (2006)

17. Rodriguez, R., Ortiz, A., Alfaro, J.: Fostering collaborative meta-value chain practices. International Journal of Computer Integrated Manufacturing 22(5), 385-394 (2009)

18. Rodriguez, R.R., Gomez, P., Franco, D., Ortiz, A.: Establishing and keeping interorganisational collaboration: Some lessons learned. International Federation for Information Processing 1, 214-222 (2007)

19. Leseure, M., Shaw, N., Chapman, G.: Performance measurement in organisational networks: an exploratory case study. International Journal of Business Performance Management 3(1), 30-46 (2001) 